\title{
Preparation of the ELISE test facility for long-pulse extraction of negative ion beams
}

\author{
R. Nocentini*, U. Fantz, M. Froeschle, B. Heinemann, W. Kraus, R. Riedl, D. Wuenderlich \\ Max Planck Institute for Plasma Physics, Boltzmannstr. 2, 85748 Garching, Germany
}

\begin{abstract}
The test facility ELISE (Extraction from a Large Ion Source Experiment) at IPP Garching, Germany, aims to demonstrate ITER-relevant negative ion beam parameters which are required for the NBI system of ITER. ELISE is equipped with a Radio Frequency driven source and an ITER-like extraction system with half the ITER size. An $\mathrm{H}^{-}$or $\mathrm{D}^{-}$ beam can be extracted for $10 \mathrm{~s}$ every 3 minutes from the continuously operating plasma source. The duration of the beam pulses is currently limited by the power supplies available at IPP. Although up to now record-setting 1 hour plasmas have been produced in $\mathrm{H}^{-}$as well as in $\mathrm{D}^{-}$, long plasma pulse operation with multiple beam blips showed a key issue: the coextracted electron current during the extraction phase is strongly dynamic and temporally instable, particularly in $\mathrm{D}^{-}$. These instabilities are likely caused by back-streaming positive ions and Cs dynamics in the source. In order to investigate the source physics in long beam pulses, an upgrade of ELISE using a steady state high voltage power supply is envisaged. This upgrade requires a new steady state diagnostic calorimeter for which a few concepts are being investigated, which make use of several thermocouples, IR thermography and water calorimetry to measure beam intensity, divergence, profile and homogeneity. In addition the suitability of a tungsten wire calorimeter to characterize the steady state beam is being examined. Shielding of delicate components in the beam line, e.g. a large DN $1250 \mathrm{~mm}$ gate valve, by means of suitable protection scrapers, is being considered. A selection of these technical solutions is presented and discussed in the paper.
\end{abstract}

Keywords: Neutral Beam Injection, ITER, negative ion source, radio frequency source, ELISE

\section{Introduction}

The test facility ELISE (Extraction from a Large Ion Source Experiment) is the first large experiment equipped with a radio frequency (RF) driven ion source for the production and extraction of negative ions at ITER-relevant parameters. The purpose of ELISE is to bridge the gap between the prototype RF sources of area (wxh): $0.3 \times 0.6 \mathrm{~m}^{2}[1,2]$ to the full ITER size sources of area: $0.9 \times 2.0 \mathrm{~m}^{2}$, thereby solving the open physics issues due to the size extrapolation. In particular the goal of ELISE is to achieve stable beam pulses at the required ITER parameters: extracted current density of $286 \mathrm{~A} / \mathrm{m}^{2}$ $\left(\mathrm{D}^{-}\right)$and $329 \mathrm{~A} / \mathrm{m}^{2}\left(\mathrm{H}^{-}\right)$, ratio of co-extracted electrons to extracted ions below one and a beam non-uniformity of less than $10 \%$ at $0.3 \mathrm{~Pa}$ filling pressure for $1 \mathrm{~h}$. The experience and the experimental results acquired with ELISE will support the design of the Neutral Beam Test Facility PRIMA in Padua [3] and of the ITER NBI system [4].

The ion source of ELISE has a size of $0.9 \times 1 \mathrm{~m}^{2}$, i.e. the same width and half the height of the ITER source. The extraction area amounts to approximately $0.1 \mathrm{~m}^{2}$. The negative ion sources of ELISE and ITER share many design features, e.g. the extraction aperture geometry and the RF-drivers design. ELISE has however been designed to facilitate diagnostic access and experimental flexibility. The ion source is equipped with 4 cylindrical drivers with wound-up RF coils. The drivers are paired up in series and powered by two $1 \mathrm{MHz}$ RF generators with up to $180 \mathrm{~kW}$ power (up to $90 \mathrm{~kW}$ per driver). The plasma is ignited and sustained by inductive coupling for up to $1 \mathrm{~h}$. The plasma expands from the drivers into the source chamber. The ion source is closed on one side by the plasma-facing grid (PG).

Two cesium ovens are installed on the vertical source side walls to evaporate Cs inside the source and produce a thin Cs layer that reduces the work function of the metallic surfaces. Negative ions are produced mainly by surface conversion of hydrogen atoms and positive ions coming in contact with the Cs-covered surfaces. The negative ions produced on the PG plasma side, near the extraction apertures, have a high chance of being extracted. The electron temperature must be below $2 \mathrm{eV}$ in front of the PG to reduce electron detachment of negative ions. For this purpose a magnetic filter field of about 2-3 $\mathrm{mT}$ is produced in front of the PG by a current of up to $5.3 \mathrm{kA}$ flowing vertically through the PG [5] and return conductors [6]. An overview of the ELISE test facility is given in $[7,8,9]$.

The extraction system consists of three grids: the PG, the extraction grid (EG), and a grounded grid (GG), with up to $15 \mathrm{kV}$ and $60 \mathrm{kV}$ voltage difference respectively with respect to the PG. The extraction grid is equipped with permanent magnets to filter the electrons which are co-extracted with the negative ions due to the same polarity. The co-extracted electrons impact on the EG surface, therefore the grid is also equipped with complex water cooling circuits to remove the heat load due to the impacting energetic electrons [10]. Each grid is composed by two grid segments (top and bottom) and contains 640 apertures arranged in a 8 groups of $5 \times 16$ apertures similarly to the ITER geometry. Beam extraction is currently possible in pulsed mode for $10 \mathrm{~s}$ every $180 \mathrm{~s}$ due to limitations of the high voltage (HV) power supplies (PS). 


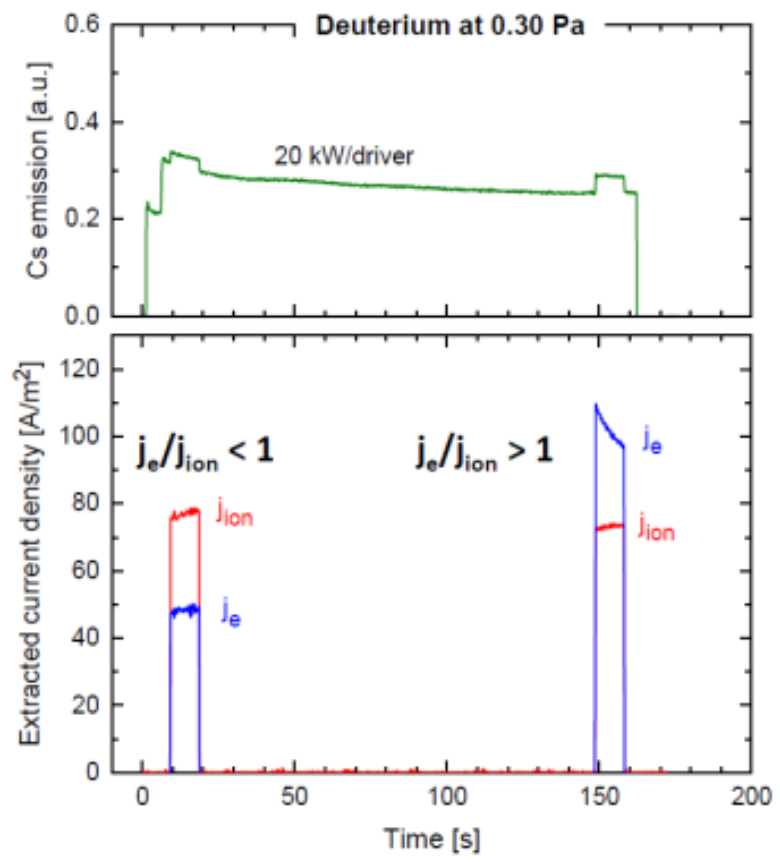

Figure 1: Top: increased signal in Cs emission spectroscopy during beam pulses; Bottom: steep increase of co-extracted $\mathrm{e}^{-}$from beam blips to beam blip and decrease of co-extracted $\mathrm{e}^{-}$currents during beam pulses.

The test facility is equipped with source [11] and beam [12] diagnostics. The beam is characterized by means of beam emission spectroscopy, with 20 lines of sight, and a diagnostic calorimeter with thermocouples, water calorimetry and IR imaging. A tungsten-wire calorimeter is used for a qualitative beam monitoring using an optical camera.

\section{Pulsed beam operation}

Plasma operation was started in ELISE in February 2013. So far ion current densities of $256 \mathrm{~A} / \mathrm{m}^{2}(\mathrm{H}) /$ $176 \mathrm{~A} / \mathrm{m}^{2}$ (D) have been reached for short $20 \mathrm{~s}$ plasma pulses with $10 \mathrm{~s}$ beam. In longer plasma pulses of up to $1 \mathrm{~h}$, with $10 \mathrm{~s}$ beam blips every $180 \mathrm{~s}$, current densities of $155 \mathrm{~A} / \mathrm{m}^{2}(\mathrm{H}) / 57 \mathrm{~A} / \mathrm{m}^{2}$ (D) have been achieved [13].

During long plasma pulses it has been observed that the ion currents extracted during beam blips tend to decrease slightly from beam blip to beam blip, while the co-extracted electron currents increase substantially, especially in deuterium operation, as shown in figure 1 . In certain beam blips the co-extracted electron current is very dynamic and decreases during the beam-on phase. This is partly attributable to the influence of backstreaming positive ions [14] which impact on the source back-plate and sputter Cs from the surface, therefore affecting the source conditioning. This release of Cs during the beam pulse can clearly be seen in the Cs emission spectroscopy, as shown in figure 1. For this reason a steady state beam extraction is desirable to study the source behavior in a more ITER-relevant regime and to optimize its performance.

\section{Upgrade to steady state beam for $1 \mathrm{~h}$}

In order to achieve $1 \mathrm{~h}$ steady state beam operation an upgrade of the HV PS has been envisaged. The desired parameters of the new power supplies are: $22 \mathrm{kV} / 70 \mathrm{~A}$ for the extraction PS (assuming $33 \mathrm{~A}$ extracted $\mathrm{H}^{-}$current and $33 \mathrm{~A}$ co-extracted $\mathrm{e}^{-}$current; $10 \mathrm{kV}$ extraction voltage and $12 \mathrm{kV}$ voltage drop across the modulator tubes) and $50 \mathrm{kV} / 35 \mathrm{~A}$ for the acceleration PS (assuming $33 \mathrm{~A}$ accelerated $\mathrm{H}^{-}$current and stripping losses $<10 \%$ ).

Almost all the mechanical components of the ELISE test facility are already steady state capable: the ion source, the extraction system grids and grid holder boxes are temperature-controlled. The RF-heated components, like the electromagnetic screens around the drivers, have been recently upgraded to an actively cooled design [15]. Also the cryogenic-pumps already allow steady state beam operation for $1 \mathrm{~h}$. Several plasma and beam diagnostics, like beam emission spectroscopy are steady state ready. The suitability of the tungsten-wire calorimeter [12] for many hours of beam-on time has been assessed. The estimated lifetime is at least 30 hours, limited by tungsten evaporation in the hottest sections of the wires. Other beam-line components, e.g. the green shield at the exit of the GG and the large gate valve, might require additional protection.

The main component which requires a complete redesign is the diagnostic calorimeter, which is currently based on inertial cooling and therefore designed for maximum $10 \mathrm{~s}$ beam-on time every $180 \mathrm{~s}$. The design of the current diagnostic calorimeter described in [12]. The current calorimeter has worked very reliably for more than two years. The IR thermography in particular has been very useful to characterize the beam, in particular for beam homogeneity and divergence, by using fit procedures. A great quantity of data has been collected and is still being analyzed [16].

The new calorimeter should keep these useful features of the current calorimeter but allow operation in steady state mode, up to $1 \mathrm{~h}$.

\section{Steady state diagnostic calorimeter}

For the design of the steady state calorimeter several concepts have been taken into account. In this paper we present the two most promising design solutions: Type 1 and Type 2. In both solutions the calorimeter is made of four plates. Each plate hosts 15x15 OFHC copper blocks which define the resolution for the measurement of the 2D beam profile. 
To validate the designs computational fluid dynamics (CFD) simulations have been performed by means of the commercial code CFX. In a first step the model geometries have been generated in the ANSYS Workbench program. For Type 1 a small plate portion with $5 \times 5$ blocks has been simulated, while for Type 2 a full plate with $15 \times 15$ blocks has been modeled. Subsequently the volumes of the water circuit as well as of the metallic parts of the calorimeter plates have been meshed with tetrahedral and, wherever possible, with hexahedral elements (e.g. for straight cooling channels). Taking into account the possibility of separated flow due to the complex water channel geometry, a SST turbulence model [17] has been used. For best results, particular care has been taken to mesh the boundary layer with a sufficient number of inflated elements (about 25) in order to achieve $y^{+}<1$. The total number of nodes for each model is approximately 5 million nodes and 10 million elements.

\subsection{Type 1 concept}

The first concept is based on a modular solution where a tiny water circuit with the shape of a spiral is placed under each copper block as shown in Figure 2. In this way the cooling of each block occurs in parallel and independently, thus minimizing heat transfer between blocks. The calorimeter plate is made of a sandwich of three brazed stainless steel plates, a layer of electrodeposited copper and OFHC copper blocks (dimensions: $39 \times 39 \times 28 \mathrm{~mm}^{3}$ ) brazed on top. The stainless steel plates form two $5 \mathrm{~mm}$ thick water manifolds as main water inlet and outlet. A spiraliform cooling circuit is embedded into the electro-deposited copper layer. Cylindrical channels perpendicular to the plate surface connect the manifolds and the spiraliform cooling circuit.

In order to achieve a uniform water flow distribution in case of many parallel water channels connected to one manifold, it is important that the pressure drop in the manifold is much smaller than the one in the parallel water spirals. As the viscosity of water decreases considerably with increasing temperature (a factor 3.5 between $20^{\circ} \mathrm{C}$ and $100{ }^{\circ} \mathrm{C}$ ), flow distribution amongst cooling circuits of the blocks becomes power loaddependent and non-uniform. These aspects have been taken into account by designing wide inlet and outlet manifolds with low average water velocity $(\mathrm{v}<0.3 \mathrm{~m} / \mathrm{s})$ and inlet channels with a small diameter and high water velocity $(\varnothing 1 \mathrm{~mm}, \mathrm{v} \approx 15 \mathrm{~m} / \mathrm{s})$. The latter represents a concentrated pressure drop of about 1.5 bar at constant inlet temperature, which ensures almost equal pressure drop for all the 900 cooling circuits. Due to its section area of $2 \times 3 \mathrm{~mm}^{2}$, the water speed in the spiraliform cooling circuit is about $2 \mathrm{~m} / \mathrm{s}$. Power load-dependent residual pressure drops of all the cooling circuits of all the blocks are calculated to be small (almost $10 \%$ of the total pressure drop) with respect to the concentrated pressure drops in the upstream inlet channels (almost $90 \%$ of the total pressure drop). The total pressure drop for one calorimeter plate is about 1.6 bar. The beam power load estimation for each block can be performed
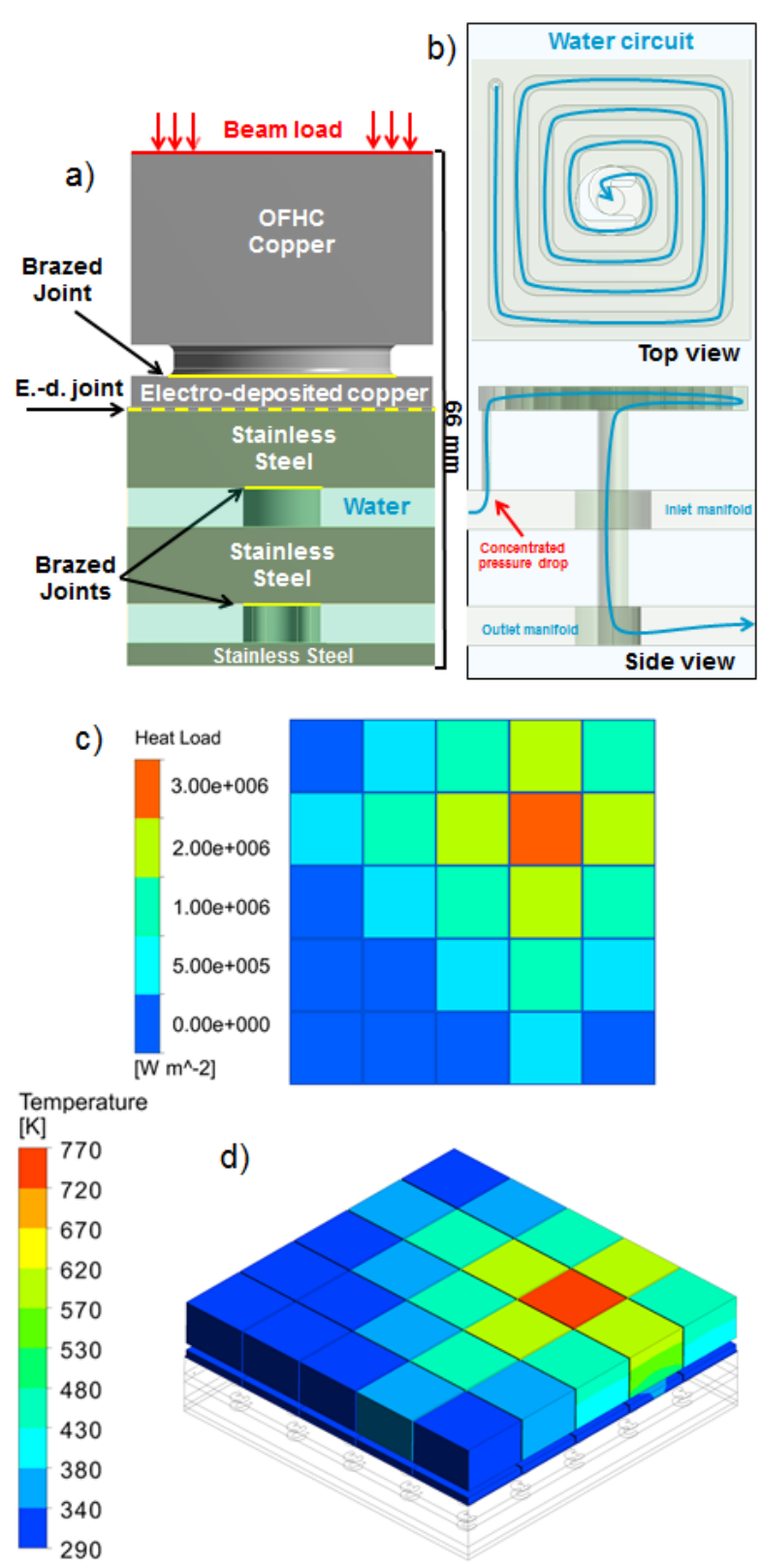

Figure 2: a): schematic view of one element of type 1 calorimeter plate with indication of joining techniques; b): schematic view of cooling circuit with water flow direction and concentrated pressure drop; c): power load used for the CFD simulation; d): temperature distribution on surface of $5 \times 5$ element model.

by embedding a thermocouple to measure the water temperature at the outlet channel of one block or by measuring the block surface temperature via IR thermography, as both values are linearly dependent on the impinging beam power.

\section{$4.2 \quad$ Type 2 concept}

The second concept, shown in Figure 3 , has a geometry similar to the current inertial calorimeter, with a few modifications in order to cope with the higher energy absorbed by the new steady operation. The calorimeter plate is made of a heavily cooled back-plate with integrated inlet and outlet manifold and 90 embedded cooling channels (section area: $2 \times 5 \mathrm{~mm}^{2}$ ). The cooling channels are milled into a copper plate and closed by an electro-deposited copper layer. The 


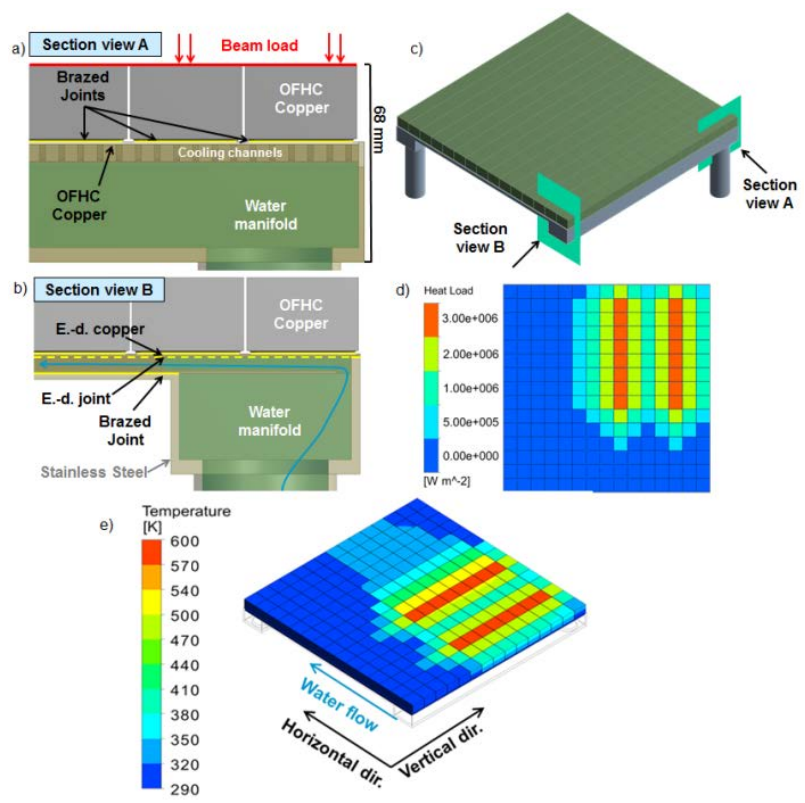

Figure 3: a), b), c): section views of calorimeter plate model in manifold region with indication of joining techniques; d): power load used for the CFD simulation; e): result of CFD simulation, the temperature of the downstream blocks is increased due to heating up of water in the channels due to the upstream blocks.

manifolds are milled into a stainless steel plate which is brazed to the copper plate. 225 OFHC copper blocks (dimensions: $39 \times 39 \times 27 \mathrm{~mm}^{3}$ ) are brazed on top of the cooling plate with a large area of contact. This solution is easier to manufacture than the Type 1 , due to the larger straight cooling channels which are less demanding to be machined and requires less electrodeposited copper. On the other hand this solution will present considerable disadvantages in terms of data evaluation: the water in cooling channels will be heated by the beam power load impinging on the first blocks and will subsequently heat up the downstream blocks, as visible in Figure 3 . In addition a certain degree of transversal heat transfer between neighboring water channels is to be expected. These effects have to be taken into account when evaluating the beam power using the block surface temperatures, or the signal from thermocouples embedded into the blocks in the vicinity of the beam-facing surface, as input data.

\section{Summary}

Within 3 years of operation the test facility ELISE has made steady progress and has achieved current densities of $256 \mathrm{~A} / \mathrm{m}^{2}(\mathrm{H}) / 176 \mathrm{~A} / \mathrm{m}^{2}$ (D) for short pulses and $155 \mathrm{~A} / \mathrm{m}^{2}(\mathrm{H}) / 57 \mathrm{~A} / \mathrm{m}^{2}$ (D) for long pulses, both at $0.3 \mathrm{~Pa}$ but at reduced RF power.

The co-extracted electron current during the extraction phase is strongly dynamic and temporally instable, particularly in $\mathrm{D}^{-}$. These instabilities are likely caused by back-streaming ions and Cs dynamics in the source [1]. In order to investigate the source physics in long beam pulses, an upgrade of ELISE using a steady state high voltage power supply is envisaged. This upgrade requires new power supplies and a new steady state diagnostic calorimeter for which two concepts are presented in the paper. In the next future, after a careful analysis of the two design concepts, the detailed plate design will be finalized. Measures for protection for the beam line components will also be assessed.

\section{Acknowledgments}

This work has been carried out within the framework of the EUROfusion Consortium and has received funding from the Euratom research and training programme 2014-2018 under grant agreement No 633053. The work is being supported by a contract from Fusion for Energy (F4E-2009-0PE-32-01), represented by Antonio Masiello. The opinions expressed herein do not necessarily reflect those of Fusion for Energy or the European Commission.

References

[1] KRAUS, W. et al. Rev. of Scientific Instruments, p. 02B104, 2012.

[2] SPETH, E. et al. Nuclear Fusion, v. 46, p. S220, 2006.

[3] SONATO, P. et al. Fusion Engineering and Design, v. 84, n. 2-6, p. 269-274, 2009.

[4] HEMSWORTH, R. et al. Nuclear Fusion, v. 49, p. 045006, 2009.

[5] NOCENTINI, R. et al. Fusion Engineering and Design, v. 84, p. 2131-2135, 2009.

[6] FRÖSCHLE, M. et al. Fusion Engineering and Design, 2013. in press; availabe online.

[7] HEINEMANN, B. et al. Fusion Engineering and Design, v. 84(2-6), p. 915-922, June 2009.

[8] HEINEMANN, B. et al. Fusion Engineering and Design, v. 86(6-8), p. 768-771, 2011. http://dx.doi.org/10.1016/j.fusengdes.2010.11.031.

[9] HEINEMANN, B. et al. Fusion Engineering and Design, 2013. in press; availlabe online.

[10] NOCENTINI, R. et al. Fusion Engineering and Design, v. 86(6-8), p. 916-919, 2011.

[11] WÜNDERLICH, D. et al. Review of Scientific Instruments, v. 84, p. 093102, 2013.

[12] NOCENTINI, R. et al. Fusion Engineering and Design, 2013. in press; available online.

[13] FANTZ, U. et al. Review of Scientific Instruments 87, 02B307, 2016.

[14] SCHIESKO, L. et al. Nuclear Fusion, v. 51, p. 113021, 2011.

[15] HEINEMANN, B. et al. Fusion Enginnering and Design, submitted.

[16] NOCENTINI, R. et al. Fusion Engineering and Design, v. 109-111, Part A, p. 673-677, 2016.

[17] MENTER, F. R. AIAA Journal, v. 32, p. 15981605, 1994.

[18] KRAUS, W. et al. Review of scientific instruments, v. 87, n. 02B315, 2016.

[19] KRAUS, W. et al. Review of scientific instruments, v. 87, n. 02B315, 2016.

[20] WÜNDERLICH, D. et al. Plasma Physics and Controlled Fusion, submitted.

[21] FRANZEN, P. et al. Fusion Engineering and Design, 2013. in press. 
[22] NOCENTINI, R. et al. 25th Symposium on Fusion Engineering (SOFE 25). 2013. p. PID2814993.

5 